tuberculosis scourge, we may be able to marshal in the foremost line, among the Roman institutions pledged to do battle in that holiest of crusades, this noble new institution of ours. And, the success of our Alliance once assured, it will need only a rational co-ordination of our forces and a wise initiative to prove to all the world, in the clearest and most eloquent way, how much has been done and is now doing in Rome, not only to promote charitable work and public health in general, but also specially, and with, if possible, even more ardent enthusiasm, to bar the advance of the terrible foe that, more than any other malady, works such awful havoc among our youngest and loveliest, and is such a potent factor in the most deadly forces that make ever so mightily, for the degeneration of the race. And it is most just that this mission should be confided to Rome-Rome, the living symbol of the most glorious traditions, the highest civilization, of our Italian stock; the mission; we would say, of proclaiming to the world that our country forgets not that first among the nations she placed the sources of health within the reach of the poorest of her sons at need, and that she is the motherland of Ramazzini.

\title{
APICAL PERCUSSION IN THE DIAGNOSIS OF EARLY PULMONARY TUBERCULOSIS.
}

\author{
By HAROLD VALLOW, \\ M.D., \\ Resident Medical Officer, Leeds Sanatorium, Gateforth, Selby.
}

I COMMENCED percussion of the extreme apices of the lungs on the advice of the late Professor Trevelyan, of the University of Leeds, who suggested I should investigate the methods employed by Krönig and others with the object of proving their value or otherwise in the diagnosis of early pulmonary tuberculosis. My results have been confirmed by the Honorary Physicians to the Leeds Sanatorium for Consumptives, the late Dr. Trevelyan, Dr. Woodcock, and Dr. Watson. After examination of $25^{\circ}$ cases of suspected pulmonary tuberculosis, I have come to the conclusion that the value of apical percussion in the diagnosis of early pulmonary tuberculosis is extraordinarily great. I have frequently been able to demonstrate the presence of a tuberculous lesion at one apex of the lung when the other physical signs have been doubtful. In one of the cases, tubercle bacilli were found in the sputum, but the site could not be ascertained except by apical percussion, and a few weeks later râles appeared at the site thus indicated. In many cases of doubtful diagnosis the method has been of very great 
value. An example is shown by the following case: A girl was examined at the central offices, and the only sign that could be found was a limitation of the resonant zone above the left clavicle. She was admitted to the Sanatorium for observation. I tested her with the subcutaneous tuberculin test, and there was a reaction to I milligramme of Koch's old tuberculin. The focal reaction-râles at the left apexproved that apical percussion had indicated the correct site of the lesion. The methods I investigated were: (I) Krönig's ; (2) Philip's ; (3) tidal percussion.

The descriptions I have read of performing Krönig's method have appeared to me to be very vague and difficult to follow. After carefully examining 250 cases, I have been able to employ a more accurate way of mapping out the resonant area. By this method I have been

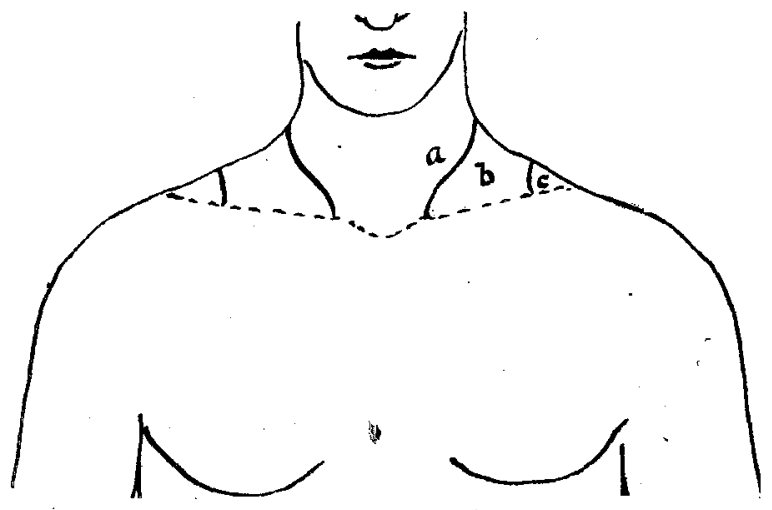

DIAGRAM I.

able to demonstrate the presence of the lesion in 80 per cent. of the early cases, and in 92 per cent. of the later ones. By Philip's method, the lesion was indicated in 50 per cent. of the cases: When examining my patients, I now map out the resonant area, and, if there is no difference in the breadth of the zone on the two sides, I employ Philip's method. I rarely find it necessary to use tidal percussion, although this might be of great value.

History. - A. Fränkel traced this method back to Seitz and Ziemssen, in 1883 . Krönig commenced percussion of the apices in 1889 , republished his method in 1902 , and in 1907 provided us with a monograph. Oestreich tested the method experimentally on post-mortem material, and obtained extremely satisfactory results. He was able to determine the presence of tubercular centres the size of a cherry provided they were not too far removed from the surface.

Krönig's Method.-From the point of view of this method, the anatomical margins of the apex must not be considered. In a normal 
apex there is a broad band of resonance above the clavicle, projecting over the shoulder-girdle; at the point where it passes over the shoulder-girdle it is called the isthmus. I have found the average breadth of the projected band of resonance immediately above the clavicle in an adult to be $2 \frac{1}{2}$ inches, and at the isthmus $\mathrm{I}_{4}^{3}$ to 2 inches.

The following method of percussing the projected resonant area has given me the best results. I stand behind the patient, who is sitting on a chair facing the window with the shoulders fully exposed, and place the forefinger of the left hand accurately in contact with the skin well up at the inner side of the neck, at an angle of $45^{\circ}$ to the middle line of the neck, the tip of the finger pointing downwards, and the centre of the finger 2 to $2 \frac{1}{2}$ inches from the lower part of the thyroid cartilage. I percuss slowly downwards and outwards, at right angles,



to a line joining the lower part of the thyroid cartilage with the junction of the outer and middle thirds of the clavicle. As soon as pulmonary resonance is reached, I mark this spot with a skin pencil. I now commence percussion at the inner side of the neck immediately above the inner end of the clavicle, and percuss outwards until pulmonary resonance is reached. I mark this spot also with a skin pencil. The upper and lower ends of the inner boundary have now been found. By joining these pencil marks, the inner boundary is obtained. The line should be slightly concave inwards above and slightly convex inwards below. It can be mapped out with slightly greater accuracy by percussing outwards and downwards at different levels, commencing in the triangular area of the neck between an imaginary line drawn between the upper and lower ends of the inner boundary and the middle line of the neck. The points at which pulmonary resonance is reached are marked with a skin pencil, and the whole of the marks joined together. The outer boundary of the resonant area is defined 
by percussing inwards from the shoulder until pulmonary resonance is reached. The outer boundary is concave outwards, and ends at the junction of the outer and middle thirds of the clavicle. The method will be much better understood by reference to the diagrams. Klebs describes a posterior band of resonance, but this is not so easily defined owing to the thickness of the muscular layer. The normal level of the apex behind is that of the first dorsal spine, and it is 2 to ${ }^{2} 4$ inches from the spine. The inner boundary slopes with its convexity towards the spinal column until it reaches the level of the second dorsal spine, when it runs downwards, parallel with and half an inch from the spine. The posterior and external line is found to run downwards with its concavity outwards, and to terminate with great regularity at the middle of the spine of the scapula. In a normal

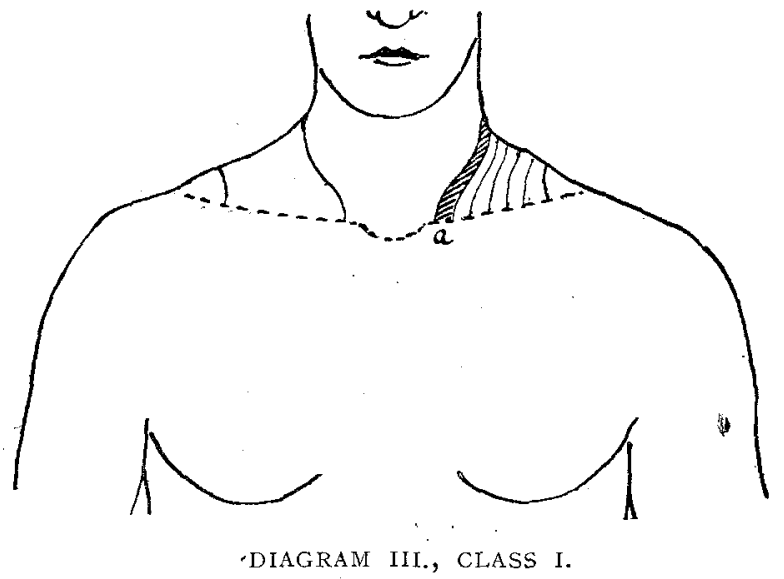

chest I have found the projected zone of the lung resonance to be equal in breadth on both sides. On an average, the breadth is $2 \frac{1}{2}$ inches on both sides immediately above the clavicle, and $I_{4}^{\frac{3}{4}}$ to 2 inches at the isthmus. In Diagram I. ( $a$ ) indicates the position of the dull note at the inner side of the neck; $(b)$ the area of lung resonance; and $(c)$ the note at the outer side of the neck.

Owing to the great difficulty in accurately describing the changes I have observed, I have represented them diagrammatically as follows:

The projected zone of lung resonance is divided by longitudinal lines into six belts. The inner and outer belts named $A$ and $A^{l}$, the' two middle belts $C$ and $C^{1}$, and the intermediate ones between $A$, and $C$, and $\mathrm{A}^{\mathbf{1}}$, and $\mathrm{C}^{1}, \mathrm{~B}$, and $\mathrm{B}^{1}$.

In a normal chest the percussion note over the six belts is. resonant.

In Class I. there is an impaired note ove: the inner belt, A, indieating commencing infiltration of the apex. 
In Class II. the note over the inner and outer belts $A$ and $A^{1}$ is impaired, probably indicating more infiltration than in Class I.

In Class III. the note over the inner and outer beits $A$ and $\mathrm{A}^{1}$ is dull (whereas in Class II. it is impaired), the middle belts are resonant, and the intermediate belts $\mathrm{B}$ and $\mathrm{B}^{1}$ are impaired. This class probably indicates strong retraction.

In Class IV. there is an impaired note over the whole of the projected zone; this needs no diagrammatic description.

The earliest change I have observed has been an impairment of note within the inner boundary of the resonant zone, thereby causing a contraction of the zone from the inner side. This is indicated by. shading representing an impaired note over $\mathrm{A}$, Class $\mathrm{I}$.

A gland behind the sterno-mastoid may give rise to an impaired

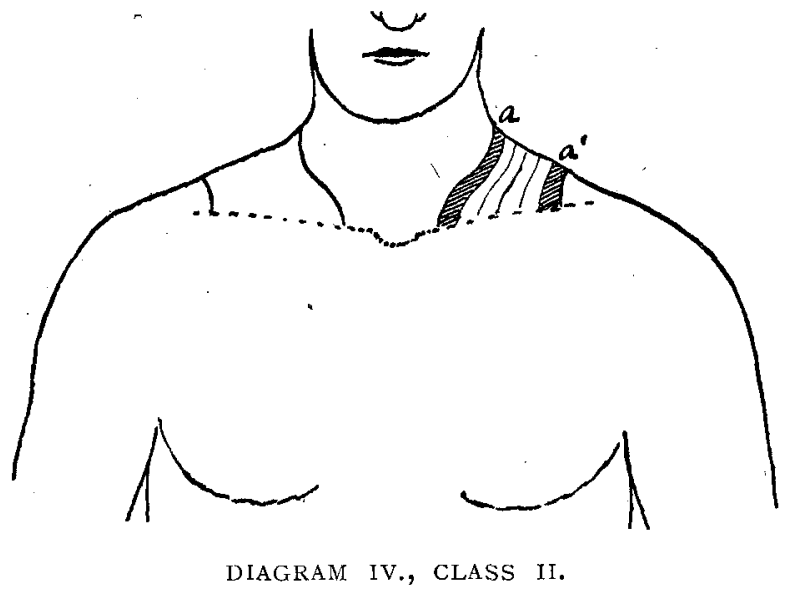

percussion note within the inner boundary, thus simulating apical disease.

The next percussion change I have observed has been an impairment of note within the inner and outer boundaries of the normal resonant zone, thereby causing a contraction from the outer and inner margins, reducing the breadth of resonance from $2 \frac{1}{2}$ inches above the clavicle to about $I \frac{3}{4}$ inches or less. The impaired note within the boundaries is indicated by shading in the illustration. I have called this change Class II.

The third change--the zone of lung resonance has been greatly contracted. In Class II. the note over the outer and inner belts was impaired, whereas in Class III. the note was dull over these belts, and impaired over the adjacent belts $B$ and $B^{1}$, leaving only a very small area of lung resonance.

By reference to the diagrammatic description, the change will be much better understood. 
The fourth change, an impaired note over the whole of the normal resonant area, all pulmonary resonance had disappeared (Class IV.). This change was only present in a few of the late cases.

Resistance to the finger is frequently of more value than the contraction of the resonant zone. The resistance can often be made out when no difference in note can be detected. It is of the utmost importance to use very light percussion, so that the percussion note can only be heard by the physician's ear. I have found this percussion change in certain other pathological conditions affecting the apex of the lung: (a) Non-tuberculous collapse of the apex; $(b)$ malignant disease of the apex ; $(c)$ apical pneumonia.

In early cases of pulmonary tuberculosis, the apical change trequently disappears as the patient's condition improves.

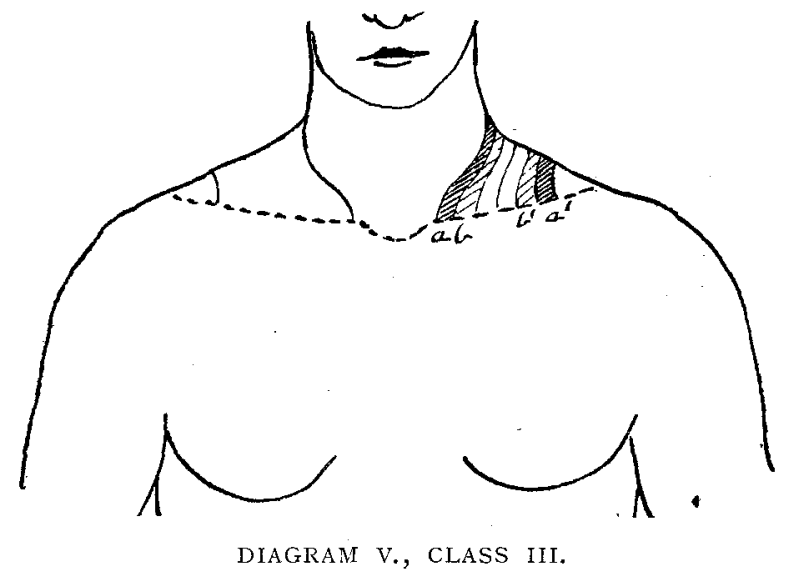

Philip's Method.-I have examined I 50 cases by this method; the lesion was indicated in 50 per cent. of the cases. The normal apex extends $I \frac{1}{2}$ to 2 inches above the clavicle. In a healthy adult the percussion note should extend a like distance, which is equal to three fingers'-breadth above the clavicle. Philip recommends percussion parallel to the clavicle. As in Krönig's method, very light percussion. is necessary. - Percuss one finger's - breadth immediately above the clavicle, and compare the note with that on the opposite side. Compare the note of the second finger's-breadth above the clavicle with that on the opposite side. Compare the note over third finger'sbreadth above the clavicle with that on the opposite side. In a normal chest, the three fingers'-breadth on each side should be resonant. The first change I have observed has been an impairment of the note over the third finger's-breadth on the affected side. The second change, an impaired note over the second finger's-breadth, dull note over the third. The third change, first finger's-breadth, impaired; second, dull; third, dull. 
Philip's Tidal Percussion.-In a healthy subject, the difference in the height of the percussion note during inspiration and expiration is one finger's-breadth; this should be equal on both sides. In early pulmonary tuberculosis, limitation of the tidal difference may be noted, and as consolidation advances the limitation of the tidal change becomes more marked.

In cases of doubtful diagnosis, tidal percussion may be of great value. I have been able to detect two changes: (a) Half a finger'sbreadth 'difference between inspiration and expiration; and $(b)$ no difference between inspiration and expiration.

Lastly, hyper-resonance above the clavicle may indicate the site of the lesion. The late Dr. Trevelyan demonstrated this sign to me on one of his cases. In estimating this sign, one has to remember that the note above the right clavicle is normally more resonant than the note above the left clavicle.

The following table comparing the signs on apical percussion with the other physical signs demonstrates its great value. I wish to thank my honorary physicians, Dr. Woodcock and Dr. Watson, for their kindness in allowing me to publish these results. The diagrams have been drawn by Dr. Watson.

Table Showing the Relation between. the Signs of Apical Percussion and the Physical Signs.

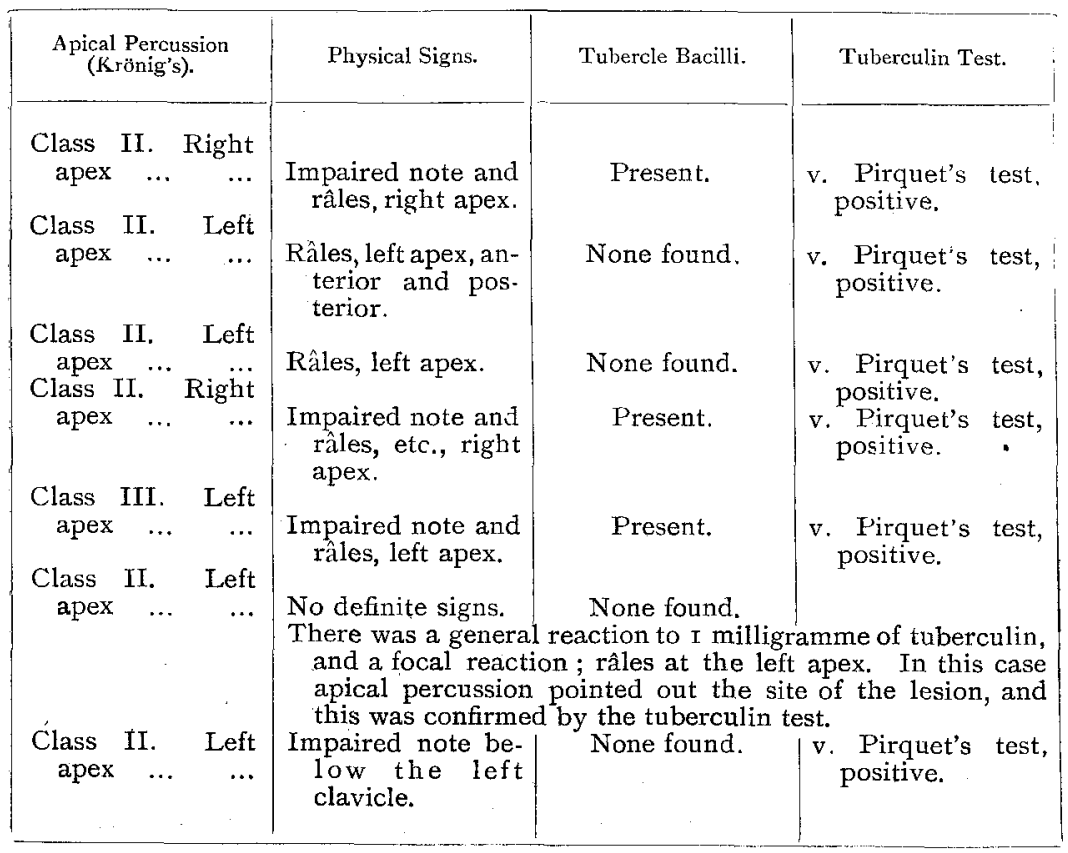

